\title{
Cost-Effectiveness of Bone SPECT/CT in Painful Total Knee Arthroplasty
}

\author{
Tim Van den Wyngaert ${ }^{1,2}$, Swetha R. Palli ${ }^{3}$, Ryan J. Imhoff ${ }^{3}$, and Michael T. Hirschmann ${ }^{4,5}$ \\ ${ }^{I}$ Nuclear Medicine, Antwerp University Hospital, Edegem, Belgium; ${ }^{2}$ Faculty of Medicine and Health Sciences, University of \\ Antwerp, Wilrijk, Belgium; ${ }^{3}$ CTI Clinical Trial and Consulting Services, Covington, Kentucky; ${ }^{4}$ Department of Orthopaedic \\ Surgery and Traumatology, Kantonsspital Baselland (Bruderholz, Liestal, Laufen), Bruderholz, Switzerland; and ${ }^{5}$ University of Basel, \\ Basel, Switzerland
}

The purpose of this study was to quantify the economic value of bone SPECT/CT versus CT or metal artifact reduction sequence (MARS)MRI for the diagnostic assessment of recurrent moderate-to-severe pain after total knee arthroplasty (TKA). Methods: An Excel-based simulation model was developed to compare bone SPECT/CT versus CT or MARS-MRI from a payer perspective. Clinical endpoints (diagnosis-delayed or otherwise, and the subsequent treatment and complications) and their corresponding cost data (2017 U.S. dollars) were obtained by performing a best evidence review of the published literature. Studies were pooled and parameters weighted by sample size. A cost-utility analysis was performed estimating the incremental cost per quality-adjusted life years gained between bone SPECT/CT and the comparative scans. One-way $( \pm 25 \%)$ sensitivity analysis was performed to gauge the model robustness. Results: For every 1,000 TKA patients, diagnostic bone SPECT/CT was expected to lead to 3 -y cost savings up to $\$ 1,867,695$ versus CT (or $\$ 622.6$ per patient per year) and $\$ 1,723,435$ versus MARS-MRI (or $\$ 574.5$ per patient per year) for a payer. With corresponding incremental quality-adjusted life years gains of 39.7 and 41.0 against CT and MARS-MRI, SPECT/CT can be considered as a cost-saving and dominant strategy in the workup of persistent/recurrent pain in TKA patients. The model was limited by the still sparse literature data, was most sensitive to imaging-related sensitivity/specificity, but proved robust for varying prevalence of surgical/nonsurgical causes of pain. Conclusion: Bone SPECT/CT is a potentially highly cost-saving and dominant imaging intervention versus CT or MARS-MR scanning in patients with recurrent and persistent knee pain after TKA.

Key Words: bone; joint/muscle; SPECT/CT; SPECT/CT; bone scintigraphy; cost-effectiveness; knee arthroplasty

J Nucl Med 2018; 59:1742-1750

DOI: 10.2967/jnumed.117.205567

\section{A}

record number of 4.7 million Americans were alive with a total knee arthroplasty (TKA) in 2010, and the annual number of procedures is projected to increase to 3.5 million by $2030(1,2)$. In parallel, the TKA revision rate has increased $105.9 \%$ between 1991 and 2010 (3). With a cost that is $60 \%$ higher than the primary

Received Nov. 20, 2017; revision accepted Mar. 15, 2018.

For correspondence or reprints contact: Tim Van den Wyngaert, Department of Nuclear Medicine, Antwerp University Hospital, Wilrijkstraat 10, 2650 Edegem, Belgium.

E-mail: tim.van.den.wyngaert@uza.be

Published online Mar. 30, 2018.

COPYRIGHT (C) 2018 by the Society of Nuclear Medicine and Molecular Imaging. procedure, this poses a considerable budgetary challenge and emphasizes the need for careful patient selection (4). The most frequent indications for revision TKA are newly onset or persistent pain (5-7), instability, stiffness, or periprosthetic joint infection (8). Even though pain recurrence after TKA is well documented, the reported prevalence varies widely (between $4.8 \%$ and $44 \%$ ). Identifying the precise cause of pain remains challenging as symptoms and history often lack specificity (9-14). This may delay a correct diagnosis, postpone optimal therapeutic intervention, increase the cost of the diagnostic workup, and can potentially adversely affect patient outcome (8).

Current modalities used in TKA imaging include conventional radiographs, stress radiographs, $\mathrm{CT}$, MRI, planar bone scintigraphy with or without SPECT, or ${ }^{18} \mathrm{~F}$-FDG PET/CT (14). Multidetector CT offers better bone and implant detail than radiographs, which are considered the preferred first-line imaging procedure (15-17). CT can assess the extent of osteolysis, periprosthetic fractures, and TKA malpositioning, but the technique is limited in differentiating inactive from active anatomic lesions (15). More recently, due to improvements in metal artifact reduction sequence (MARS) protocols, there is renewed interest in the use of MRI in this setting (15). In parallel, fully integrated SPECT/CT devices have overcome the limited spatial resolution of SPECT-only imaging, resulting in significantly improved diagnostic accuracy and providing a unique combination of simultaneous evaluation of skeletal anatomy and physiology $(14,16)$. Moreover, the use of bone-affine tracers with SPECT/CT offers the advantage of linking bone turnover patterns with biomechanical information on TKA placement and loading (18). This additional information can assist in selecting appropriate clinical management and assessing whether further surgical treatment is warranted $(14,16,17,19)$. However, it is unclear whether these clinical benefits translate into successful economic and humanistic (e.g., quality-of-life [QoL]) outcomes. Therefore, this economic simulation study aimed to quantify the potential economic value and cost utility of bone SPECT/CT compared with other imaging technologies (CT, MARS-MRI) in assessing persistent or recurrent knee pain after TKA from a payer perspective.

\section{MATERIALS AND METHODS}

\section{Model Scaffold}

The diagnostic algorithm published by Park et al. combines physical examination, radiographs, and laboratory workup to stratify patients toward further diagnostic procedures (6). Following this decision-tree, instability/malposition and acute infection were not considered within the current model, as these conditions may be adequately characterized without advanced imaging techniques. However, additional imaging 
may be required for the accurate diagnosis of implant loosening/wear/ osteolysis, chronic low-grade infection, and patellofemoral problems (includes anterior knee pain, extensor mechanism problems, avascular necrosis, and patellar overstuffing/maltracking). On the basis of an extensive literature review, the model focused on the differential diagnosis of these 3 conditions as these represent the most frequent causes of post-TKA pain (Fig. 1) $(14,16,20-41)$. The model also assumed: 1 primary causal condition; a nondiagnostic CT would be complemented with a MARS-MRI and vice versa, and an equal split between CT and MARS-MRI when bone SPECT/CT was nondiagnostic; the second imaging procedure was always diagnostic (to avoid an infinite loop); in case of a nondiagnostic scan, a subsequent scan was done after a 6-mo medical pain management regimen; medical management involved a 70:30 mix of nonsteroidal antiinflammatory drugs (NSAIDs) plus physiotherapy or steroid injections with occasional nonnarcotic analgesics (e.g., acetaminophen); with regular office visits for pain-monitoring and treatment of any adverse events (including general, cardiovascular or gastrointestinal toxicity, skin flares, or sepsis); and medical management did not result in long-term relief given the severity of the underlying condition and associated functional limitations.

The study modeled a hypothetical cohort of 1,000 TKA patients experiencing recurrent moderate-to-severe pain over a 3-y period. If diagnosed with a noninfectious cause, patients undergo a 1-stage revision TKA: removal of TKA components and implantation of revision TKA (42). Primary patellar resurfacing was done in the case of patellofemoral issues, whereas $13.8 \%$ of the loosening group also received secondary patellar resurfacing (Table 1) (21). For the chronic infection cohort, a 2-stage exchange arthroplasty was performed: removal of all components, placement of a temporary antibiotic-laden cement spacer with subsequent extended intravenous or oral antibiotic regimen to eradicate the infection, followed by revision TKA (43). To model specificity, $10 \%$ of the cohort was assumed to have pain caused by other conditions that did not require a surgical intervention, as firstline workup was expected to detect most of these patients before entering the modeled pathway (Fig. 1). The model also accounted for the risk of major and minor complications among the surgery patients (Table 2). Patients correctly treated with surgical intervention (true-positives) were assumed to have no further treatment beyond the standard postsurgery management (e.g., physiotherapy and monitoring) and to remain painfree for the duration of the study (Table 3). All improperly treated patients (i.e., the false-positives and -negatives) were assumed to have failed the treatment and to have derived no benefits. These patients continued to experience painful knees of undetermined origin and spend at least 2 y (44) in identifying the true cause of their condition before undergoing delayed TKA revision. During this wait-and-watch strategy, patients received annual radiographs and a CT scan and intensive medical management (70:30 mix of NSAIDs and steroid injections) with physiotherapy. Concurrently, quarterly visits to an orthopedic surgeon or general practitioner for consulting and management reasons were

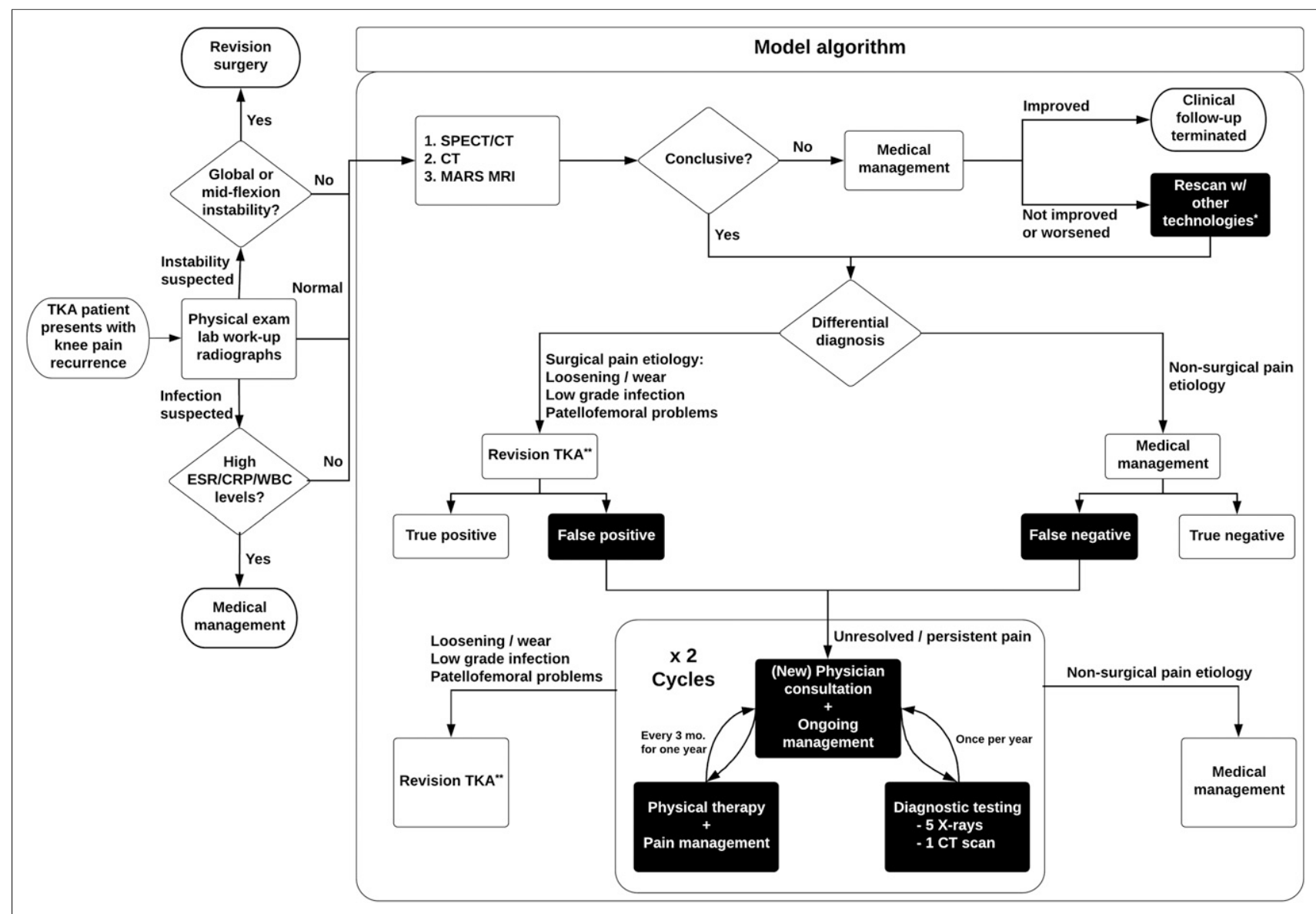

* For secondary rescan among the nondiagnostic patients, the imaging choice would be either $\mathrm{CT}$ or MRI. In the SPECT/CT arm, a 50:50 split between CT and MRI scans is assumed for the nondiagnostic cases

"* Revision due to low-grade infection involves prosthesis removal, insertion of a temporary spacer, antibitic treatment, and placement of new prosthesis; revision due to patelofemoral problems includes primary patellar resurfacing

FIGURE 1. Model scaffold: proposed care pathway. CRP = C-reactive protein; ESR = erythrocyte sedimentation rate; WBC = white blood cells. 
TABLE 1

Demographic, Disease, and Imaging Model Parameters

\begin{tabular}{|c|c|c|c|}
\hline Parameter & Base case & Range & Reference \\
\hline \multicolumn{4}{|l|}{ Demographics } \\
\hline Age $<65$ y & $40.4 \%$ & $0 \%-100 \%$ & \\
\hline $\begin{array}{l}\text { Medicare-to-commercial } \\
\text { reimbursement conversion factor }\end{array}$ & 1.5 & $1.17-1.95$ & $\begin{array}{l}\text { American Hospital Association's aggregate } \\
\text { hospital payment-to-cost ratio }(66)\end{array}$ \\
\hline \multicolumn{4}{|l|}{ Disease-related } \\
\hline Prevalence of loosening/wear & $70.38 \%$ & $10 \%-94.95 \%$ & $(14,16,20-26,28,30-32,34-41)$ \\
\hline Prevalence of low-grade infection & $16.68 \%$ & $14.81 \%-80.52 \%$ & $(14,16,20-25,28,30,31,34-41,51,63)$ \\
\hline $\begin{array}{l}\text { Prevalence of patellofemoral } \\
\text { problems }\end{array}$ & $12.94 \%$ & $0 \%-68.75 \%$ & \\
\hline \multicolumn{4}{|l|}{ Imaging-scan-related } \\
\hline \multicolumn{4}{|l|}{ SPECT/CT } \\
\hline Scan cost & $\$ 239.38$ & - & $\begin{array}{l}\text { Medicare national payment amount for } \\
\text { CPT code } 78320 \text { (49) }\end{array}$ \\
\hline Sensitivity & $98.42 \%$ & $97 \%-100 \%$ & $(14,16,17)$ \\
\hline Specificity & $91.34 \%$ & $68.5 \%-100 \%$ & $(17)$ \\
\hline Nondiagnostic rate & $3.17 \%$ & $0 \%-8.83 \%$ & $(14,16,17)$ \\
\hline \multicolumn{4}{|l|}{ CT } \\
\hline Scan cost & $\$ 115.20$ & - & $\begin{array}{l}\text { Medicare national payment amount for } \\
\text { CPT code } 73700 / 73701 / 73702 \text { (49) }\end{array}$ \\
\hline Sensitivity & $80.60 \%$ & $80 \%-81 \%$ & $(67,68)$ \\
\hline Specificity & $74 \%$ & $50 \%-98 \%$ & $(69,70)$ \\
\hline Nondiagnostic rate & $16.13 \%$ & $12.1 \%-20.2 \%$ & (63) \\
\hline \multicolumn{4}{|l|}{ MARS-MRI } \\
\hline Scan cost & $\$ 646.72$ & - & $\begin{array}{l}\text { Medicare national payment amount for CPT } \\
\text { code } 73721 / 73722 / 73723(49)\end{array}$ \\
\hline Sensitivity & $82.87 \%$ & $67 \%-100 \%$ & $(24,67,69,71,72)$ \\
\hline Specificity & $84.52 \%$ & $83 \%-88 \%$ & $(71,72)$ \\
\hline Nondiagnostic rate & $8.47 \%$ & $0 \%-16.1 \%$ & $(63,71)$ \\
\hline
\end{tabular}

included. True-negatives continued to be on a medical management pathway. These event pathways were constructed on the basis of a literature review and clinical expert opinion.

A best evidence review of PubMed articles published between January 1, 2006, and March 31, 2017 was performed to obtain default parameter values. Selection criteria included English-language studies considered to be most relevant (e.g., adult human subjects, in vivo) to the clinical and imaging application(s) in question. Case reports and case series with a sample size of fewer than 15 (arbitrarily chosen) were excluded. For the imaging-related parameters, studies assessing sensitivity, specificity, or nondiagnostic rates were identified. Descriptive data from single-modality series were used if direct comparison data were unavailable. Sample size weighted estimates were synthesized in the case of multiple data sources to mitigate outlier bias (45).

\section{Health States}

Seven health states were considered in total (Fig. 2). After revision surgery, a transition was assumed within $3 \mathrm{mo}$, to one of the following: full-benefit state, an early failed/limited-benefit state, or death. The latter was an absorbing state because of surgical mortality. A successfully revised patient was allocated to the full-benefit health state until the end of the model. False-positives and -negatives entered the failed/ limited-benefit state. After the implementation of the wait-and-watch strategy, they would be correctly treated for the underlying cause of the pain, before transitioning to the full-benefit state.

\section{Utilities}

Utility factors ( $0=$ death; $1=$ perfect health) were assigned to all health states (based on orthopedic literature data) to adjust survival for QoL and were expressed as quality-adjusted life years (QALYs) by multiplying the length of time spent in a health state with its corresponding utility (Table 4) (46). To represent the short-term negative impact of TKA revision on QoL (47) (reduced mobility, pain, and nonlethal complications after surgery), a one-time deduction was applied by multiplying the acute procedure toll with the recovery time (3 mo) to the patient QALYs in the procedure year (48). On the basis of published evidence, the disutility of having a revision TKA was set at -0.19 with no distinction placed on the aseptic and septic cause given the low prevalence of chronic infection in our model $(16.7 \%)$.

\section{Cost Estimates}

To represent the payer's perspective, the 2017 national average Medicare professional and technical fees were extracted on the basis of the specific current procedural terminology (CPT) codes for each modality (49). Baseline revision arthroplasty procedure cost was 
TABLE 2

Revision Surgery and Unresolved Pain Base Case Model Parameters

\begin{tabular}{|c|c|c|c|}
\hline Parameter & Base case & Range & Reference \\
\hline Revision surgery cost & $\$ 22,693$ & $\$ 12,063-27,136$ & $\begin{array}{l}2014 \text { Health Care Cost and Use Project Database } \\
\text { (ICD-9 Proc primary codes: 00.80, 00.81, 00.82, } \\
00.83,00.84,80.06,81.55)(50)\end{array}$ \\
\hline Medicare payment-to-cost (\%) & $88.50 \%$ & $2.1 \%-3.5 \%$ & (66) \\
\hline Medicare reimbursement & $\$ 20,083$ & $\$ 10,675-24,015$ & (66) \\
\hline Private payer payment-to-cost (\%) & $143.70 \%$ & $2.1 \%-3.5 \%$ & (66) \\
\hline Private payer reimbursement & $\$ 32,610$ & $\$ 17,334-38,994$ & (66) \\
\hline Spacer cost & $\$ 4,466$ & $\$ 4,255-4,677$ & (51) \\
\hline Patelloplasty cost & $\$ 2,719$ & $\$ 2,039-3,399$ & (52) \\
\hline $\begin{array}{l}\text { Proportion of loosening patients } \\
\text { receiving patella resurfacing }\end{array}$ & $13.80 \%$ & $10.4 \%-17.3 \%$ & (21) \\
\hline \multicolumn{4}{|l|}{$\begin{array}{l}\text { Risk and costs associated with } \\
\text { Medical complications }\end{array}$} \\
\hline Probability of MI & $4.41 \%$ & $0.8 \%-7.7 \%$ & $(27,40,53)$ \\
\hline Ml cost & $\$ 21,308$ & $\$ 15,981-26,635$ & (53) \\
\hline Probability of pneumonia & $1.36 \%$ & $1.4 \%-15.4 \%$ & $(40,53)$ \\
\hline Pneumonia cost & $\$ 11,926$ & $\$ 10,684-31,793$ & $(53,54)$ \\
\hline Probability of PE/DVT & $4.90 \%$ & $0.8 \%-10.71 \%$ & $(27,40,41,53,55)$ \\
\hline PE/DVT cost & $\$ 12,770$ & $\$ 9,578-15,963$ & (53) \\
\hline $\begin{array}{l}\text { Probability of infection (joint, UTI, } \\
\text { or sepsis) }\end{array}$ & $5.36 \%$ & $0.7 \%-15.4 \%$ & $(40,53)$ \\
\hline Infection cost & $\$ 26,219$ & $\$ 19,664-32,773$ & (53) \\
\hline Probability of RF & $7.95 \%$ & $1.7 \%-15.4 \%$ & $(27,40,41)$ \\
\hline RF cost & $\$ 38,305$ & $\$ 34,821-41,789$ & (54) \\
\hline Probability of Gl bleed & $4.41 \%$ & $4.3 \%-7.7 \%$ & $(27,40)$ \\
\hline GI bleed cost & $\$ 16,533$ & $\$ 11,063-22,004$ & (54) \\
\hline Probability of death & $0.96 \%$ & $0.01 \%-1.2 \%$ & $(47,53)$ \\
\hline Cost of death & $\$ 16,910$ & $\$ 12,683-21,138$ & (53) \\
\hline $\begin{array}{l}\text { Postsurgery medical management } \\
\text { including physiotherapy }\end{array}$ & $\$ 3,366$ & $\$ 2,524-4,207$ & $(73,74)$ \\
\hline \multicolumn{4}{|l|}{ Unresolved pain } \\
\hline \multicolumn{4}{|l|}{ Office visit } \\
\hline Probability & $100 \%$ & $0 \%-100 \%$ & Assumption \\
\hline Number per year & 1 & - & Assumption \\
\hline Cost per visit & $\$ 127.59$ & $\$ 109-146$ & $\begin{array}{l}\text { Medicare national payment amount for CPT } \\
\text { codes } 99214-99215(49)\end{array}$ \\
\hline \multicolumn{4}{|l|}{ Surgeon consult } \\
\hline Number per year & 1 & - & Assumption \\
\hline Cost per consult & $\$ 187.70$ & $\$ 166-209$ & $\begin{array}{l}\text { Medicare national payment amount for CPT } \\
\text { codes } 99204-99205(49)\end{array}$ \\
\hline \multicolumn{4}{|l|}{ Set of radiographs/CT scans } \\
\hline Number per year & 1 & - & Assumption (5 radiographs and $1 \mathrm{CT}$ scan) \\
\hline Cost per set & $\$ 155$ & $1 \geq$ & 2017 physician fee schedule CPT code 73564 (49) \\
\hline \multicolumn{4}{|l|}{ Physiotherapy } \\
\hline Number per year & 12 & - & Assumption \\
\hline Cost per visit & $\$ 116$ & - & 2017 physician fee schedule CPT code 73564 (49) \\
\hline \multicolumn{4}{|l|}{ Steroid injection } \\
\hline Probability & $30 \%$ & $0 \%-100 \%$ & (75) \\
\hline Number per year & 5 & - & (75) \\
\hline Cost per visit & $\$ 76$ & $\$ 57-95$ & (76) \\
\hline
\end{tabular}

$\mathrm{MI}=$ myocardial infarction; PE/DVD = pulmonary embolism/deep venous thrombosis; UTI = urinary tract infection; RF = renal failure; GI = gastrointestinal. 
TABLE 3

Medical Management Base Case Model Parameters

\begin{tabular}{|c|c|c|c|}
\hline Parameter & Base case & Range & Reference \\
\hline Occasional analgesics: acetaminophen, opioids & $\$ 117$ & $\$ 87-146$ & (53) \\
\hline \multicolumn{4}{|l|}{$\begin{array}{l}\text { Nonsurgical regimen } 1 \text { annual costs: office visits, devices, } \\
\text { physical therapy, NSAIDs, or acetaminophen }\end{array}$} \\
\hline Initial year & $\$ 1,249$ & $\$ 587-1,715$ & $(53,74)$ \\
\hline Subsequent years & $\$ 949$ & $\$ 446-1,304$ & $(53,74)$ \\
\hline \multicolumn{4}{|l|}{ Adverse events } \\
\hline Probability of general toxicity (year 1 ) & $2.76 \%$ & $2.1 \%-3.5 \%$ & (53) \\
\hline Probability of general toxicity (year $2+$ ) & $2.11 \%$ & $1.6 \%-2.6 \%$ & $(53)$ \\
\hline General toxicity cost & $\$ 57$ & $\$ 43-71$ & (53) \\
\hline Probability of cardiovascular toxicity & $0.12 \%$ & $0.1 \%-1.5 \%$ & (53) \\
\hline Risk of death due to cardiovascular toxicity & $5.29 \%$ & $4.0 \%-6.6 \%$ & (53) \\
\hline Cardiovascular toxicity cost & $\$ 21,308$ & $\$ 14,317-23,861$ & (53) \\
\hline Probability of GI toxicity & $0.23 \%$ & $0.2 \%-0.3 \%$ & $(53)$ \\
\hline Risk of death due to GI toxicity & $2.68 \%$ & $2.1 \%-3.4 \%$ & (53) \\
\hline Gl toxicity cost & $\$ 11,145$ & $\$ 8,564-14,274$ & (53) \\
\hline Nonsurgical regimen 2 annual costs: office visits, injections & $\$ 1,240$ & $\$ 424-1915$ & $(53,74)$ \\
\hline Adverse events & & & (53) \\
\hline Probability of skin flares & $24.00 \%$ & $18 \%-30 \%$ & (53) \\
\hline Cost of skin flares & - & $\$ 0-25$ & $(53)$ \\
\hline Probability of sepsis & $0.0013 \%$ & $0.001 \%-0.002 \%$ & (53) \\
\hline Risk of death due to sepsis & $8.35 \%$ & $6.3 \%-10.4 \%$ & $(53)$ \\
\hline Sepsis cost & $\$ 15,700$ & $\$ 12,065-20,108$ & (53) \\
\hline Probability of nonsurgical regimen 1 (vs regimen 2) & $70 \%$ & $0 \%-100 \%$ & $(75)$ \\
\hline
\end{tabular}

derived from 2014 Health Care Cost and Use Project data (50) with addon costs for each additional complexity (e.g., antibiotic-laden spacer and antibiotic regimen for infectious patient (51), patellar resurfacing (52), and any perioperative complication(s) $(27,40,41,47,53-55))$. Medical management costs accrued during the 3 -mo postsurgery period accounting for care provided in inpatient settings, physician services, and postacute care facilities (e.g., skilled nursing or rehabilitation facilities, home health, hospice, or long-term care) were included. Cost estimates were inflated to 2017 U.S. dollars using the Bureau of Labor Statistics' US Medical Care Consumer Price Index (56). Non-Medicare (commercial) payments were calculated for persons aged 65 or younger based on Medicare payments. Given the study's short time frame, discounting was not considered.

\section{Outcomes}

For each imaging modality: the total $3-y$ cost burden was the cumulative cost of diagnostic imaging scan and rescans; revision surgery (surgery, perioperative complications) and postsurgical management; medical management (office visits, physiotherapy, NSAIDs, injections, analgesics, and any potential adverse events associated with these treatments); and monitoring (radiographs, CT, surgeon consultations, office visits) during the wait-and-watch approach. Total QALYs were calculated as the sum of the utility of each of the 7 health states multiplied by the time spent in each health state.

Cost-effectiveness of SPECT/CT was defined as the ratio of incremental difference in costs and QALYs between SPECT/CT and the comparator technique and expressed as the incremental cost-effectiveness ratio of SPECT/CT per QALY gained.

\section{Sensitivity Analysis}

To assess the impact of the individual model parameters and robustness of the findings, a 1-way sensitivity analysis was conducted by varying each model parameter by $\pm 25 \%$ of its base case estimate.

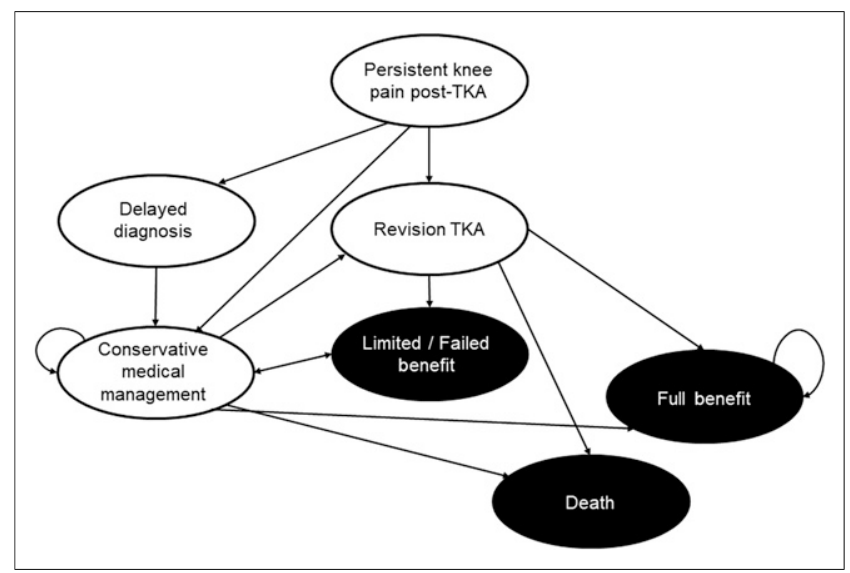

FIGURE 2. Health state diagram representation. 
TABLE 4

Utilities (Time): Base Case Model Parameters

\begin{tabular}{lccc}
\hline \multicolumn{1}{c}{ Parameter } & Base case & Range & Reference \\
\hline Wait time for identifying cause/treatment decision (y) & 2 & - & Assumption \\
\hline Prerevision & 0.51 & $0.31-0.76$ & $(33,42,47,73,76,77)$ \\
\hline Surgery/postop recovery disutility (3 mo) & 0.19 & $0.1-0.35$ & $(42,46-48,73)$ \\
Minor complications disutility (3 mo) & 0.04 & $0.02-0.05$ & $(78)$ \\
Major complications disutility (3 mo) & 0.06 & $0.04-0.08$ & $(78)$ \\
Postsuccessful revision surgery & 0.86 & $0.78-0.9$ & $(46,47,73)$ \\
Postfailed revision surgery & 0.47 & $0.51-0.55$ & $(48,73,78)$ \\
Medical management disutility & 0.08 & - & $(76)$ \\
\hline
\end{tabular}

Further, the impact of the $10 \%$ prevalence of nonsurgical causes on the results was explored in a separate sensitivity analysis, to increase the applicability of the model's findings in other care settings. This model was built using Excel 2013 (Microsoft Corp.).

\section{RESULTS}

For every 1,000 TKA patients experiencing recurrent and persistent moderate-to-severe pain and undergoing diagnostic bone SPECT/CT, CT, or MARS-MRI, the total 3-y burden was expected to be $\$ 37,133,788, \$ 39,001,483$, and $\$ 38,857,223$, respectively (Fig. 3). Therefore, SPECT/CT was found to result in $\$ 1,867,695$ lesser costs for a payer versus CT over 3 y or $\$ 622.6$ per patient per year. SPECT/CT's lower costs against CT appeared to be primarily driven by its improved accuracy, thus avoiding undue surgeries and ad hoc medical management for the major duration of the study period. Switching from MARS-MRI was also found to save the payer approximately $\$ 1,723,435$ ( $\$ 574.5$ per patient per year). SPECT/CT's relatively higher sensitivity and specificity reduced overall use, which in turn lowered costs for the hybrid technology cohort. A total of 908, 926, and 914 revision surgeries were performed in the SPECT/CT, CT, and MARS-MRI cohorts, respectively, of which $1.7 \%, 18.8 \%$, and $16.9 \%$ were deemed as late/delayed procedures because of a false-negative diagnosis, respectively.

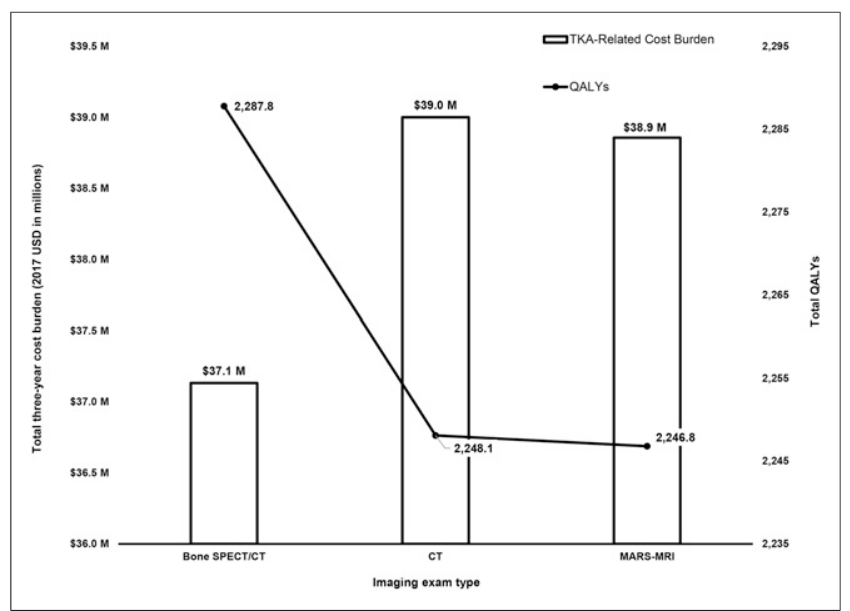

FIGURE 3. Economic burden and QALYs, by imaging type.
In terms of QALYs, SPECT/CT, CT, and MARS-MRI were found to be associated with QALYs of 2,287.8, 2,248.1, and 2,246.8, respectively: that is, QALY gains of 39.7 and 41.0 for SPECT/CT versus CT and MARS-MRI, respectively. The life-years gained were a direct function of the bone SPECT/CT cohort receiving the highest successful revision surgery rate early during the study period. CT's nonoptimal management because of its lower diagnostic rate and specificity was also found to have contributed to its lower QALYs. Since SPECT/CT was found to lower costs and improve QALYs, this imaging modality can be considered as a highly costeffective and dominant strategy for diagnosing recurrent and persistent knee pain in TKA patients.

\section{Sensitivity Analysis}

The model was most sensitive to imaging-related parameters, especially sensitivity/specificity, and wait-and-watch-period related costs (Fig. 4). SPECT/CT was found to be always cost-saving/ neutral even with a $\pm 25 \%$ change in their base case parameter values. In addition, changing the prevalence of nonsurgical causes of painful TKA affected the cost-savings and QALYs gained by SPECT/CT over CT and MARS-MRI in a proportional way, but it remained cost-saving and dominant (Supplemental Fig.1; supplemental materials are available at http://jnm.snmjournals.org).

\section{DISCUSSION}

Despite plateauing TKA failure times (mean, 5.9 y) (57-59), increasing primary TKA rates are driving the growing number of revision procedures $(\sim 101,290$ in the United States in 2017) (2). With an average hospitalization cost of $\$ 29,584$ (50), the total inpatient revision TKA burden in 2017 alone aggregated to nearly $\$ 3$ billion, highlighting the impact on budgets and increasing strain on surgeons, patients, and health systems (2,50). A prompt and accurate diagnosis is pivotal, as the outcome of revision is very poor (failure rate up to $80 \%$ ) if the root cause is left undetermined before surgery (60). Diagnostic algorithms to streamline the workup and maximize their yield firmly rely on imaging procedures $(6,14)$. It is therefore not surprising that imaging services account for $18.2 \%$ of payments of knee osteoarthritis-related health care expenditure, exceeding the cost of outpatient office evaluations and prescription nonnarcotic analgesic medications (61). Hence, interventions that can improve diagnostic accuracy and assist surgeon decision making will be of paramount importance for optimal patient management, long-term outcomes, and budget control. Integrated bone SPECT/CT is the newest entry in 


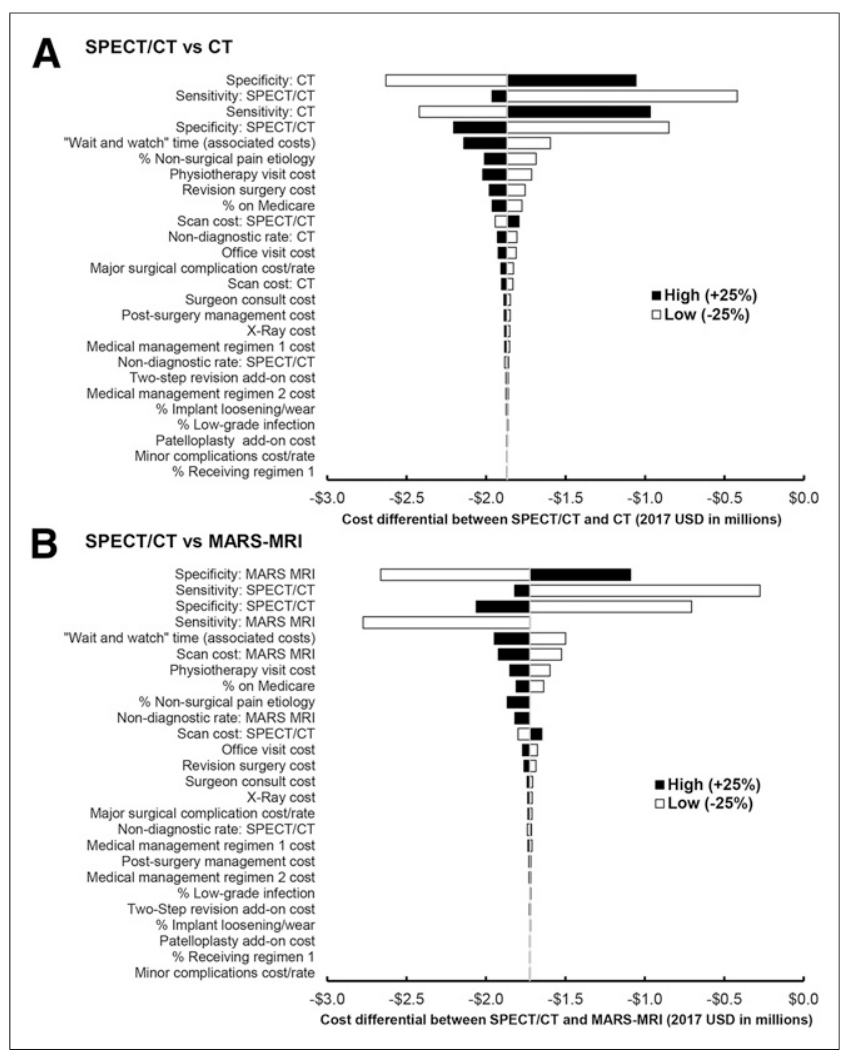

FIGURE 4. One-way sensitivity analysis (tornado diagram) for SPECT/ CT vs. CT (A) and MARS-MRI (B).

this space and is considered superior to conventional bone SPECT imaging because of its improved resolution, attenuation and scatter correction, and accurate anatomic localization (62). Indeed, very high diagnostic accuracies of bone SPECT/CT have recently been reported for evaluating knee prosthesis patients, translating into a change in diagnosis or treatment plan in nearly $50.7 \%$ $(16 \%-85.5 \%)$ of cases $(14,16,17,19)$ compared with the impact of MRI or CT, which was only $36 \%-48.8 \%(24,63,64)$. The current study, to our knowledge, is the first to evaluate the value of bone SPECT/CT from a cost perspective.

For every 1,000 patients experiencing moderate-to-severe persistent pain after TKA, the 3 -y burden was calculated to be $\$ 37.1, \$ 39.0$, and \$38.9 million for diagnostic SPECT/CT, CT, or MARS-MRI, respectively. SPECT/CT's cost savings (per patient per year of $\$ 622.6$ and $\$ 574.5$ vs. CT and MARS-MRI, respectively) are driven by its higher diagnostic accuracy and reduction of unnecessary revision surgeries (18 and 6 procedures for every 1,000 CT/MARS-MRI patients switching to SPECT/CT). In addition, avoiding surgeries saved 17 (vs. CT) and 14 (vs. MARS-MRI) more lives, thereby improving the SPECT/CT cohort's survival by $2 \%$ and $1 \%$, respectively. SPECT/CT was also found to be associated with QALY gains of 39.7 and 41.0 compared with CT and MARS-MRI, making it a dominant intervention. The additional life-years gained by the SPECT/CT cohort are likely realized by redirecting patients sooner to the appropriate surgical intervention compared with other techniques, whereas CT's nonoptimal management (e.g., high nondiagnostic rate) further lowered QALYs in that group. Indeed, early and timely management at relieving pain may prevent the domino effect of a chronic failed state on a patient's QoL. Conservatively, our model did not assume an increase in pain severity during the 2-y wait-and-watch period, even though this may be important $(44,65)$.

Incorporating novel imaging techniques such as SPECT/CT in the presurgery workup may contribute to improved selection of appropriate surgical approach. Indeed, identifying the origin of the pain and whether or not it has a surgically rectifiable cause is critical to optimize patient management. Coupled with the anticipated rise in revision procedures, SPECT/CT may prove to be an important component to optimize revision arthroplasty effectiveness. We recognize that the management of painful TKA requires a multidisciplinary approach involving surgeons, physiotherapists, and pain management teams (7), and the optimal use of SPECT/CT will require a further intensive collaboration of the referring orthopedic surgeon and the nuclear medicine physician or radiologist (14). This could be facilitated by the introduction of multidisciplinary team discussions, similar to those ubiquitously established in the oncology setting.

Like every economic analysis, this model is limited by its simplistic real-world representation. In particular, it focuses only on the top 3 of most common intrinsic pathologies requiring surgery, and assumes a singular causal condition. Conflicting reports exist in implicating aseptic (polyethylene wear, prosthetic loosening, and instability) and septic indications as the primary mechanism for failed TKA. Variability also exists across patient characteristics, failure modes, procedure types, and use across hospitals and regions, which the model does not address (21). The reader should therefore carefully assess the applicability of our findings to his or her own context. It should also be acknowledged that available literature evaluating the accuracy of imaging tests is relatively sparse, and the published studies often had small patient numbers and differed with respect to image acquisition protocols (which may evolve over the time) and reference standards (typically a composite of clinical, radiologic, laboratory, and surgical follow-up). None of the included studies on SPECT/CT or CT implemented MAR techniques that may further improve their accuracy. However, this limitation in our dataset applied to both techniques and did not favor one above the other. Taken together, our results are subject to the heterogeneity present in current literature data but are sufficiently provocative to merit further research.

\section{CONCLUSION}

For every 1,000 patients experiencing moderate-to-severe persistent pain after TKA, the total 3-y burden was calculated to be $\$ 37.1$, \$39.0, and \$38.9 million for bone SPECT/CT, CT, or MARS-MRI, respectively, leading to SPECT/CT's per patient per year cost savings of $\$ 622.6$ (vs. CT) and $\$ 574.5$ (vs. MARS-MRI). With corresponding incremental QALY gains of 39.7 and 41.0 against CT and MARS-MRI, SPECT/CT can be considered as a cost-saving and dominant strategy for orthopedic knee diagnostic purposes. Future evaluation of this technique in a larger number of patients and multiple centers, possibly in a prospective and controlled fashion, would help to more confidently address the value of this technique.

\section{DISCLOSURE}

This study was sponsored by GE Healthcare. Swetha R. Palli and Ryan J. Imhoff are employees of CTI Clinical Trial and Consulting Services, Inc., which is a paid consultant to GE Healthcare. Dr. Hirschmann reports personal fees from DepuySynthes, Lima, 
Symbios, Smith\&Nephew, and Arthrex, as well as grants from Finceramica, Italy, outside the submitted work. No other potential conflict of interest relevant to this article was reported.

\section{REFERENCES}

1. Maradit Kremers H, Larson DR, Crowson CS, et al. Prevalence of total hip and knee replacement in the United States. J Bone Joint Surg Am. 2015;97:1386-1397.

2. Kurtz S, Ong K, Lau E, Mowat F, Halpern M. Projections of primary and revision hip and knee arthroplasty in the United States from 2005 to 2030. J Bone Joint Surg Am. 2007;89:780-785.

3. Cram P, Lu X, Kates SL, Singh JA, Li Y, Wolf BR. Total knee arthroplasty volume, utilization, and outcomes among Medicare beneficiaries, 1991-2010. JAMA. 2012;308:1227-1236.

4. Burns AW, Bourne RB, Chesworth BM, MacDonald SJ, Rorabeck CH. Cost effectiveness of revision total knee arthroplasty. Clin Orthop. 2006; (446):29-33.

5. Baker PN, van der Meulen JH, Lewsey J, Gregg PJ. The role of pain and function in determining patient satisfaction after total knee replacement: data from the National Joint Registry for England and Wales. J Bone Joint Surg Br. 2007;89: 893-900.

6. Park CN, White PB, Meftah M, Ranawat AS, Ranawat CS. Diagnostic algorithm for residual pain after total knee arthroplasty. Orthopedics. 2016;39:e246-e252.

7. Toms AD, Mandalia V, Haigh R, Hopwood B. The management of patients with painful total knee replacement. J Bone Joint Surg Br. 2009;91:143-150.

8. Mandalia V, Eyres K, Schranz P, Toms AD. Evaluation of patients with a painful total knee replacement. J Bone Joint Surg Br. 2008;90:265-271.

9. Elson DW, Brenkel IJ. A conservative approach is feasible in unexplained pain after knee replacement: a selected cohort study. J Bone Joint Surg Br. 2007;89: 1042-1045.

10. Brander VA, Stulberg SD, Adams AD, et al. Predicting total knee replacement pain: a prospective, observational study. Clin Orthop. 2003;27-36.

11. Meftah M, Ranawat AS, Ranawat CS. The natural history of anterior knee pain in 2 posterior-stabilized, modular total knee arthroplasty designs. $J$ Arthroplasty. 2011;26:1145-1148.

12. Wylde V, Hewlett S, Learmonth ID, Dieppe P. Persistent pain after joint replacement: prevalence, sensory qualities, and postoperative determinants. Pain. 2011; 152:566-572.

13. Hirschmann MT, Becker R. The Unhappy Total Knee Replacement: A Comprehensive Review and Management Guide. 1st ed. Cham, Switzerland: Springer International Publishing; 2015:XXVI, 823.

14. Hirschmann MT, Amsler F, Rasch H. Clinical value of SPECT/CT in the painful total knee arthroplasty (TKA): a prospective study in a consecutive series of 100 TKA. Eur J Nucl Med Mol Imaging. 2015;42:1869-1882.

15. Sneag DB, Bogner EA, Potter HG. Magnetic resonance imaging evaluation of the painful total knee arthroplasty. Semin Musculoskelet Radiol. 2015;19:40-48.

16. Hirschmann MT, Konala P, Iranpour F, Kerner A, Rasch H, Friederich NF. Clinical value of SPECT/CT for evaluation of patients with painful knees after total knee arthroplasty: a new dimension of diagnostics? BMC Musculoskelet Disord. 2011;12:36.

17. Al-Nabhani K, Michopoulou S, Allie R, et al. Painful knee prosthesis: can we help with bone SPECT/CT? Nucl Med Commun. 2014;35:182-188.

18. Rasch H, Falkowski AL, Forrer F, Henckel J, Hirschmann MT. 4D-SPECT/CT in orthopaedics: a new method of combined quantitative volumetric $3 \mathrm{D}$ analysis of SPECT/CT tracer uptake and component position measurements in patients after total knee arthroplasty. Skeletal Radiol. 2013;42:1215-1223.

19. Arıcan P, Okudan Tekin B, Sefizade R, Naldoken S, Bastug A, Ozkurt B. The role of bone SPECT/CT in the evaluation of painful joint prostheses. Nucl Med Commun. 2015;36:931-940.

20. Niinimäki T, Eskelinen A, Makela K, Ohtonen P, Puhto AP, Remes V. Unicompartmental knee arthroplasty survivorship is lower than TKA survivorship: a 27-year Finnish registry study. Clin Orthop. 2014;472:1496-1501.

21. Bozic KJ, Kamath AF, Ong K, et al. Comparative epidemiology of revision arthroplasty: failed THA poses greater clinical and economic burdens than failed TKA. Clin Orthop. 2015;473:2131-2138.

22. Mortazavi SM, Molligan J, Austin MS, Purtill JJ, Hozack WJ, Parvizi J. Failure following revision total knee arthroplasty: infection is the major cause. Int Orthop. 2011;35:1157-1164.

23. Dalury DF, Pomeroy DL, Gorab RS, Adams MJ. Why are total knee arthroplasties being revised? J Arthroplasty. 2013;28:120-121.

24. Vessely MB, Frick MA, Oakes D, Wenger DE, Berry DJ. Magnetic resonance imaging with metal suppression for evaluation of periprosthetic osteolysis after total knee arthroplasty. J Arthroplasty. 2006;21:826-831.
25. Patil N, Lee K, Huddleston JI, Harris AH, Goodman SB. Aseptic versus septic revision total knee arthroplasty: patient satisfaction, outcome and quality of life improvement. Knee. 2010;17:200-203.

26. Robertsson O. W-Dahl A. The risk of revision after TKA is affected by previous HTO or UKA. Clin Orthop. 2015;473:90-93.

27. Schairer WW, Vail TP, Bozic KJ. What are the rates and causes of hospital readmission after total knee arthroplasty? Clin Orthop. 2014;472:181-187.

28. Lyons MC, MacDonald SJ, Somerville LE, Naudie DD, McCalden RW. Unicompartmental versus total knee arthroplasty database analysis: is there a winner? Clin Orthop. 2012;470:84-90.

29. Johnson AJ, Sayeed SA, Naziri Q, Khanuja HS, Mont MA. Minimizing dynamic knee spacer complications in infected revision arthroplasty. Clin Orthop. 2012; 470:220-227.

30. Kim KT, Lee S, Ko DO, Seo BS, Jung WS, Chang BK. Causes of failure after total knee arthroplasty in osteoarthritis patients 55 years of age or younger. Knee Surg Relat Res. 2014;26:13-19.

31. Sharkey PF, Lichstein PM, Shen C, Tokarski AT, Parvizi J. Why are total knee arthroplasties failing today: has anything changed after 10 years? J Arthroplasty. 2014;29:1774-1778.

32. Parratte S, Lunebourg A, Ollivier M, Abdel MP, Argenson JN. Are revisions of patellofemoral arthroplasties more like primary or revision TKAs. Clin Orthop. 2015;473:213-219.

33. Baker P, Cowling P, Kurtz S, Jameson S, Gregg P, Deehan D. Reason for revision influences early patient outcomes after aseptic knee revision. Clin Orthop. 2012; 470:2244-2252.

34. Le DH, Goodman SB, Maloney WJ, Huddleston JI. Current modes of failure in TKA: infection, instability, and stiffness predominate. Clin Orthop. 2014;472: 2197-2200.

35. Metsna V, Vorobjov S, Martson A. Prevalence of anterior knee pain among patients following total knee arthroplasty with nonreplaced patella: a retrospective study of 1778 knees. Medicina (Kaunas). 2014;50:82-86.

36. Kasahara Y, Majima T, Kimura S, Nishiike O, Uchida J. What are the causes of revision total knee arthroplasty in Japan? Clin Orthop. 2013;471:1533-1538.

37. Koh IJ, Cho WS, Choi NY, Kim TK. Causes, risk factors, and trends in failures after TKA in Korea over the past 5 years: a multicenter study. Clin Orthop. 2014;472: 316-326.

38. van Kempen RW, Schimmel JJ, van Hellemondt GG, Vandenneucker H, Wymenga AB. Reason for revision TKA predicts clinical outcome: prospective evaluation of 150 consecutive patients with 2-years followup. Clin Orthop. 2013;471: 2296-2302.

39. Hossain F, Patel S, Haddad FS. Midterm assessment of causes and results of revision total knee arthroplasty. Clin Orthop. 2010;468:1221-1228.

40. Gooding CR, Masri BA, Duncan CP, Greidanus NV, Garbuz DS. Durable infection control and function with the prostalac spacer in two-stage revision for infected knee arthroplasty. Clin Orthop. 2011;469:985-993.

41. Greidanus NV, Peterson RC, Masri BA, Garbuz DS. Quality of life outcomes in revision versus primary total knee arthroplasty. J Arthroplasty. 2011;26:615-620.

42. Peersman G, Jak W, Vandenlangenbergh T, Jans C, Cartier P, Fennema P. Costeffectiveness of unicondylar versus total knee arthroplasty: a Markov model analysis. Knee. 2014;21(suppl 1):S37-S42.

43. Lichstein P, Su S, Hedlund H, et al. Treatment of periprosthetic knee infection with a two-stage protocol using static spacers. Clin Orthop. 2016;474:120-125.

44. Piscitelli P, Iolascon G, Innocenti M, et al. Painful prosthesis: approaching the patient with persistent pain following total hip and knee arthroplasty. Clin Cases Miner Bone Metab. 2013;10:97-110.

45. Toney LK, Kim RD, Palli SR. The economic value of hybrid single-photon emission computed tomography with computed tomography imaging in pulmonary embolism diagnosis. Acad Emerg Med. 2017;24:1110-1123.

46. Soohoo NF, Sharifi H, Kominski G, Lieberman JR. Cost-effectiveness analysis of unicompartmental knee arthroplasty as an alternative to total knee arthroplasty for unicompartmental osteoarthritis. J Bone Joint Surg Am. 2006;88:1975-1982.

47. Mather RC 3rd, Hug KT, Orlando LA, et al. Economic evaluation of access to musculoskeletal care: The case of waiting for total knee arthroplasty. $B M C$ Musculoskelet Disord. 2014;15:22.

48. Slover J, Espehaug B, Havelin LI, et al. Cost-effectiveness of unicompartmental and total knee arthroplasty in elderly low-demand patients: a Markov decision analysis. J Bone Joint Surg Am. 2006;88:2348-2355.

49. Physician fee schedule. 2017. Centers for Medicare \& Medicaid Services website. https://www.cms.gov/apps/physician-fee-schedule/search/search-criteria.aspx. Accessed July 3, 2018

50. Agency for Healthcare Research and Quality. Healthcare Cost and Utilization Project - 2014 data. Healthcare Cost and Utilization Project website. https:// hcupnet.ahrq.gov/\#setup. Accessed July 3, 2018. 
51. Kalore NV, Maheshwari A, Sharma A, Cheng E, Gioe TJ. Is there a preferred articulating spacer technique for infected knee arthroplasty? A preliminary study. Clin Orthop. 2012;470:228-235.

52. N.C. Industrial Commission medical fees section. CPT codes and fees (CPT code 27438). N.C. Industrial Commission. http://www.ic.nc.gov/ncic/pages/00000a. htm. Accessed September 6, 2018.

53. Losina E, Paltiel AD, Weinstein AM, et al. Lifetime medical costs of knee osteoarthritis management in the United States: impact of extending indications for total knee arthroplasty. Arthritis Care Res (Hoboken). 2015;67:203-215.

54. Iribarne A, Burgener JD, Hong K, et al. Quantifying the incremental cost of complications associated with mitral valve surgery in the United States. J Thorac Cardiovasc Surg. 2012;143:864-872.

55. Järvenpää J, Kettunen J, Miettinen H, Kroger H. The clinical outcome of revision knee replacement after unicompartmental knee arthroplasty versus primary total knee arthroplasty: 8-17 years follow-up study of 49 patients. Int Orthop. 2010;34: 649-653.

56. United States Bureau of Labor Statistics (BLS). US medical care consumer price index. 2017. BLS website. http://data.bls.gov/cgi-bin/surveymost?cu. Accessed July 3, 2018.

57. Schroer WC, Berend KR, Lombardi AV, et al. Why are total knees failing today? Etiology of total knee revision in 2010 and 2011. J Arthroplasty. 2013;28:116119.

58. Lombardi AV Jr, Berend KR, Adams JB. Why knee replacements fail in 2013: patient, surgeon, or implant? Bone Joint J. 2014;96-B:101-104.

59. Bozic KJ, Kurtz SM, Lau E, et al. The epidemiology of revision total knee arthroplasty in the United States. Clin Orthop. 2010;468:45-51.

60. Laskin RS. The painful knee. Orthopedics. 1999;22:869-870.

61. Weick JW, Bawa HS, Dirschl DR. Hyaluronic acid injections for treatment of advanced osteoarthritis of the knee: utilization and cost in a national population sample. J Bone Joint Surg Am. 2016;98:1429-1435.

62. Huellner MW, Strobel K. Clinical applications of SPECT/CT in imaging the extremities. Eur J Nucl Med Mol Imaging. 2014;41(suppl 1):S50-S58.

63. Horger M, Eschmann SM, Pfannenberg C, et al. Added value of SPECT/CT in patients suspected of having bone infection: preliminary results. Arch Orthop Trauma Surg. 2007;127:211-221.

64. Sofka CM, Potter HG, Figgie M, Laskin R. Magnetic resonance imaging of total knee arthroplasty. Clin Orthop. 2003;129-135.

65. Hoogeboom TJ, van den Ende $\mathrm{CH}$, van der Sluis G, et al. The impact of waiting for total joint replacement on pain and functional status: a systematic review. Osteoarthritis Cartilage. 2009;17:1420-1427.
66. American Hospital Association (AHA). Trendwatch chartbook 2016. Trends affecting hospitals and health systems. AHA website. http://www.aha.org/research/ reports/tw/chartbook/2016/2016chartbook.pdf. Accessed July 3, 2018.

67. Zajonz D, Wuthe L, Tiepolt S, et al. Diagnostic work-up strategy for periprosthetic joint infections after total hip and knee arthroplasty: a 12-year experience on 320 consecutive cases. Patient Saf Surg. 2015;9:20.

68. He C, Lu Y, Jiang M, Feng J, Wang Y, Liu Z. Clinical value of optimized magnetic resonance imaging for evaluation of patients with painful hip arthroplasty. Chin Med J. 2014;127:3876-3880.

69. Sutter R, Hodek R, Fucentese SF, Nittka M, Pfirrmann CW. Total knee arthroplasty MRI featuring slice-encoding for metal artifact correction: reduction of artifacts for stir and proton density-weighted sequences. AJR. 2013;201:13151324 .

70. Termaat MF, Raijmakers PG, Scholten HJ, Bakker FC, Patka P, Haarman HJ. The accuracy of diagnostic imaging for the assessment of chronic osteomyelitis: a systematic review and meta-analysis. J Bone Joint Surg Am. 2005;87:24642471.

71. Plodkowski AJ, Hayter CL, Miller TT, Nguyen JT, Potter HG. Lamellated hyperintense synovitis: potential MR imaging sign of an infected knee arthroplasty. Radiology. 2013;266:256-260.

72. Li AE, Sneag DB. Greditzer HGt, Johnson CC, Miller TT, Potter HG. Total knee arthroplasty: diagnostic accuracy of patterns of synovitis at MR imaging. Radiology. 2016;281:499-506.

73. Ruiz D Jr, Koenig L, Dall TM, et al. The direct and indirect costs to society of treatment for end-stage knee osteoarthritis. J Bone Joint Surg Am. 2013;95:14731480 .

74. Pasquale MK, Louder AM, Cheung RY, et al. Healthcare utilization and costs of knee or hip replacements versus pain-relief injections. Am Health Drug Benefits. 2015;8:384-394.

75. Desmeules F, Dionne CE, Belzile E, Bourbonnais R, Fremont P. The burden of wait for knee replacement surgery: effects on pain, function and health-related quality of life at the time of surgery. Rheumatology (Oxford). 2010;49:945-954.

76. Hatoum HT, Fierlinger AL, Lin SJ, Altman RD. Cost-effectiveness analysis of intra-articular injections of a high molecular weight bioengineered hyaluronic acid for the treatment of osteoarthritis knee pain. J Med Econ. 2014;17:326-337.

77. Winther SB, Foss OA, Wik TS, et al. 1-year follow-up of 920 hip and knee arthroplasty patients after implementing fast-track. Acta Orthop. 2015;86:78-85.

78. Odum SM, Troyer JL, Kelly MP, Dedini RD, Bozic KJ. A cost-utility analysis comparing the cost-effectiveness of simultaneous and staged bilateral total knee arthroplasty. J Bone Joint Surg Am. 2013;95:1441-1449. 